DOI: https://doi.org/10.24127/ajpm.v8i1.1740

\title{
LEMBAR KERJA PESERTA DIDIK BERBASIS CABRI 3D UNTUK MENINGKATKAN PEMAHAMAN KONSEP MATEMATIS SISWA
}

\author{
Benny Hendriana ${ }^{1}$ \\ ${ }^{1}$ Pendidikan Matematika, Universitas Muhammadiyah Prof. DR. Hamka \\ E-mail: benny_hendriana@uhamka.ac.id ${ }^{l)}$
}

Received 26 December 2018; Received in revised form 24 March 2019; Accepted 3 May 2019

\begin{abstract}
The research aims to develop a Worksheet with Cabri $3 D$ that is able to improve students' conceptual understanding. This study uses a Research and Development model. This research was conducted at Gameel Akhlaq IT Middle School. The results of the initial validation from experts and practitioners, the feasibility aspect of the content has an average of $85.32 \%$ or can be categorized very well. In this aspect, the material in the LKPD is in accordance with SK and KD. For the feasibility aspect, presentation has an average of $83.93 \%$ in the excellent category. In the presentation aspect, LKPD is complete and supports the improvement of understanding of concepts. For aspects of language assessment has an average of $81.41 \%$ in the good sagat category. In the aspect of language assessment LKPD is communicative, in accordance with the level of development of students, integration of thinking paths, and use of terms, symbols or icons.
\end{abstract}

Keywords: Cabri 3D; conceptual understanding; worksheet.

\section{PENDAHULUAN}

Matematika sebagai ratu ilmu pengetahuan dibutuhkan sebagai alat bantu dalam menyelesaikan permasalahan dalam kehidupan seharihari. Pada pembelajaran di sekolah matematika bertujuan mempersiapkan pola pikir siswa agar dapat berpikir secara logis, kritis, analitis, sistematis, dan kreatif. Pengetahuan yang didapatkan siswa di sekolah haruslah dirasakan bermakna, oleh karena itu sangat penting mengaitkan antara pengalaman hidup seorang siswa dengan konsep matematika dalam pembelajaran di kelas. Pembelajaran yang dirasa bermakna oleh siswa akan bertahan lebih lama dalam ingatan (long term memory) sesuai dengan teori kognitif Ausubel. Salah satu cara agar proses pembelajaran menjadi bermakna dan menyenangkan adalah melibatkan penggunaan media dalam pembelajaran yang dapat membantu mempermudah dalam penyampian konsep, sehingga pembelajaranpun menjadi lebih menarik, efektif, dan efisien.

Pemahaman konsep matematis adalah suatu kemampuan agar siswa dapat memahami arti atau konsep matematis dari situasi serta fakta yang diketahuinya. Pada tingkat Sekolah Menengah Pertama, kemampuan pemahaman konsep matematis siswa masih rendah, karena masih banyaknya guru yang melakukan proses pembelajaran secara konvensional (Sari, 2018).

Dalam proses pembelajaran matematika, pemahaman konsep merupakan dasar kemampuan berpikir tingkat tinggi (HOTS). pemahaman konsep juga merupakan salah satu proses berpikir untuk menyelesaikan permasalahan sehari-hari. Berpikir secara matematis dapat diartikan mengembangkan ide matematis, menilai suatu proses matematisasi dan abstraksi, mengembangkan kompetensi, serta menggunakannya untuk memahami matematika itu sendiri. Implikasinya 
adalah mengarahkan guru untuk merancang pembelajaran yang baik sehingga dapat membantu peserta didik mengkonstruk pemahamannya sendiri dan mengaitkannya dengan pengalaman sehari-hari sehingga pembelajaran menjadi bermakna. Dalam pembelajaran matematika sangat diperlukan penggunaan media pembelajaran untuk membantu mehamkan konsep matematika yang bersifat abstrak pada siswa. Menurut Yeni (2011) penggunaan media pembelajaran dapat meningkatkan pemahaman konsep geometri siswa.

Salah satu pemanfaatan media dalam pembelajaran matematika adalah penggunaan software Cabri 3D. Melalui program ini peserta didik dapat mengeksplorasi, mengamati, dan membuat bangun-bangun geometri yang dapat dilihat secara tiga dimensi. Cabri $3 D$ merupakan salah satu Dynamic Geometry Software yang mampu membantu memvisualisasi dan pemodelan dalam geometri sesuai hasil penelitian (Oldknow \& Tetlow, 2008) dan (Kösa \& Karakuş, 2010).

Cabri 3D dapat membantu meningkatkan kemampuan pemahaman konsp siswa (Gürbüz \& Gülburnu, 2013). Kemampuan pemahaman konsep matematis siswa khususnya pada materi geometri dapat terlihat pada kemampuan pemahaman spasial. Menurut (Hartatiana, Darhim, \& Nurlaelah, 2017) kemampuan pemahaman spasial diartikan sebagai kemampuan kognitif seseorang dalam memproses, memanipulasi, dan mempresentasikan objek spasial. Menurut salah satu hasil penelitian di Turki, penggunaan media pembelajaran Cabri $3 D$ dapat meningkatkan kemampuan spasial rotasi siswa pada materi geometri (Baki, Kosa, \& Guven, 2011). Kemampuan spasial pada penelitian ini merupakan kemampuan siswa dalam membayangkan rotasi benda 3 dimensi, karena media pembelajaran Cabri $3 D$ mampu menyajikan objek geometri yang dapat diputar dan dilihat dari segala arah. Salah satu keunggulan dari Cabri $3 D$ adalah dalam memvisualisasikan konsep bangun ruang, selain itu siswa juga dapat dengan mudah mencoba membuat benda-benda yang berhubungan dengan bangun ruang, menentukan ukurannya, luas permukaannya, atau menentukan volumenya sehingga pada akhirnya peserta didik mampu mengkonstruk sendiri konsep bangun ruang tersebut.

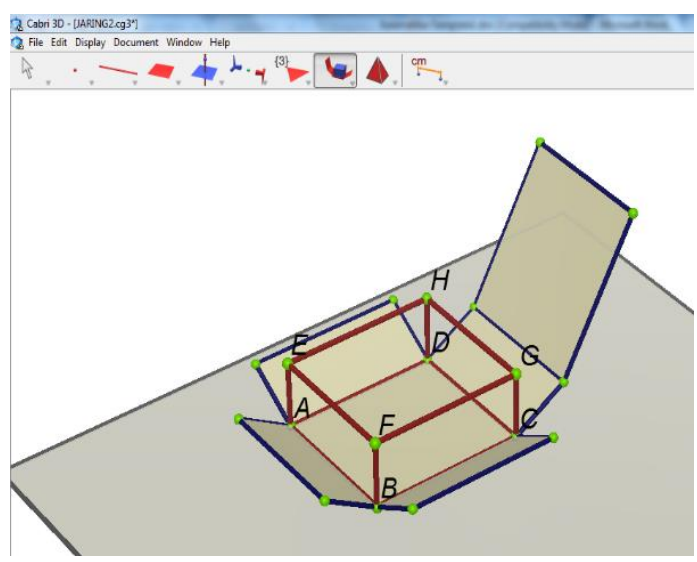

Gambar 1. Tampilan Cabri $3 D$

Menurut (Akhirni, 2015) penggunaan Cabri 3D sangat berdapkan positif bagi hasil belajar motivasi siswa. Selain itu menurut hasil penelitian (Priatna, 2017) juga mengatakan bahwa penggunaan Cabri $3 D$ dalam pembelajaran dapat meningkatkan pemahaman konsep, kreativitas siswa, serta kemampuan pemecahan masalah siswa secara simultan. Hasil tersebut juga sejalan dengan (E, Widiyaningsih. E, 2013) bahwa penggunaan Cabri 3D mampu membuat pembelajaran menjadi lebih efektif sehingga mampu berpengaruh dalam kemampuan pemecahan masalah siswa. Cabri $3 D$ juga dapat dikembangkan dengan media pembelajaran lain sehingga mampu membantu siswa dalam mengkosntruk pengetahuannya sendiri (Istitho'ah, 2017). Dari berbagai hasil penelitian di 
atas menunjukan bahwa penggunaan Cabri 3D sangat berpengaruh positif bagi siswa, untuk memaksimalkan proses pembelajaran tersebut maka diperlukanlah sebuah Lembar Kerja Peserta Didik yang dapat membantu mempermudah siswa dalam mengkonstruksi proses berpikirnya. Lembar Kerja Peserta Didik (LKPD) merupakan salah satu bahan ajar cetak yang sampai saat ini masih banyak digunakan oleh guru. Penggunaan LKPD dalam proses pembelajaran dapat memberikan peluang yang lebih besar kepada siswa untuk memperoleh prestasi belajar yang lebih baik.

LKPD yang telah digunakan siswa selama ini hanya berisikan rangkuman materi dan kumpulan rumus untuk menyelesaikan soal yang versifat rutin saja, sehingga banyak siswa yang masih kesulitan jika menghadapi soal-soal yang sedikit beda atau tidak rutin. Berdasarkan permasalahan di atas serta hasil penelitian, maka peneliti berencana Mengembangkan Lembar Kerja Peserta Didik Berbasis Software Cabri 3D. Tujuan dari penelitian ini untuk mengembangkan Lembar Kerja Peserta Didik Berbasis Cabri 3D yang mampu meningkatkan kemampuan pemahaman konsep siswa pada materi geometri.

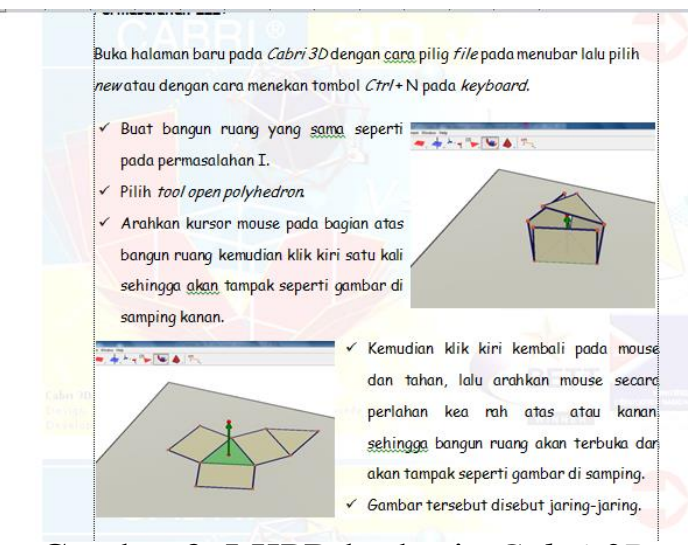

Gambar 2. LKPD berbasis Cabri 3D

\section{METODE PENELITIAN}

Pengembangan LKPD ini menggunakan jenis penelitian pengembangan (research and development). Metode penelitian dan pengembangan adalah metode penelitian yang digunakan untuk menghasilkan produk tertentu, dan menguji keefektifan produk tersebut. Penelitian jenis ini berbeda dengan penelitian pendidikan lainnya karena tujuannya adalah mengembangkan produk berdasarkan uji coba untuk kemudian direvisi sampai menghasilkan produk yang layak pakai. Tahap pengembangan Dick \& Carey diadaptasi ke dalam penelitian pengembangan ini menjadi 4 tahap, antara lain:

\section{Tahap Analisis Kebutuhan}

Tahap ini bertujuan untuk mengkaji tujuan dari produk yang akan dikembangkan. Produk yang akan dikembangkan adalah Lembar Kerja Peserta Didik (LKPD) berbasis software Cabri 3D. Peneliti akan melakukan analisis kurikulum untuk menentukan produk yang sesuai dengan tuntutan kurikulum. Analisis kurikulum akan menghasilkan tema yang disesuaikan dengan Kompetensi Isi dan Kompetensi Dasar. Selain itu, tahap ini akan menentukan dan menetapkan LKPD yang akan dikembangkan dalam satu satuan program tertentu.

\section{Tahap Desain Produk}

Hasil dari analisis kebutuhan selanjutnya akan menentukan desain produk yang akan dikembangkan. Pada tahap ini meliputi penentuan komponen LKPD, konsep dari materi, jenis tugas yang diberikan, soal evaluasi, gambar, artikel, contohcontoh, serta layout dan tampilan dari LKPD. 


\section{Tahap Validasi dan Evaluasi}

Tahap ini merupakan tahapan inti yang berupa rangkaian penilaian pengembangan produk. Tahapan pravalidasi dilakukan dengan mengkonsultasikan produk awal kepada pakar (ahli) baik dibidang matematika maupun dibidang ICT. Validasi terhadap desain awal dilakukan oleh pakar yang sudah berpengalaman untuk menilai produk yang dirancang. Hasil dari evaluasi dan saran dari ahli/ pakar digunakan untuk memperbaiki dan merevisi produk yang sedang dikembangkan. Rangkaian selanjutnya dari tahap validasi dan evaluasi adalah tahap uji keterbacaan. LKPD yang sudah dinyatakan baik oleh pakar selanjutnya diuji coba pada peserta didik di SMP sebagai calon pengguna. LKPD diterapkan pada proses pembelajaran matematika di SMP untuk kemudian peserta didik menilai dan memberi masukan terhadap LKPD tersebut. Selain itu, uji keterbacaan juga diuju cobakan ke sesama guru matematika di sekolah untuk mendapatkan masukan dalam rangka penyempurnaan produk.

\section{Tahap Produk Akhir}

Pada tahap ini dihasilkanlah produk akhir berupa LKPD yang sudah diperbaiki berdasarkan masukan dari tahapan validasi dan evaluasi. Produk akhir siap diproduksi secara massal dan disebarkan sebagai LKPD dalam proses pembelajaran. Dalam penelitian ini pengembangan hanya sampai pada tahap evaluasi formatif. Hasil dari evaluasi formatif dilakukan sebagai masukan atau input untuk memperbaiki produk awal.

Instrumen dalam penelitian ini berupa lembar saran dan komentar serta kuesioner. Isi dari kuesioner meliputi form penilaian untuk ahli/pakar dan juga from penilaian untuk peserta didik. Instrumen kelayakan LKPD pembelajaran menggunakan skala Likert dengan alternatif jawaban: sangat baik, baik, cukup, kurang dan sangat kurang. Agar diperoleh data kuantitatif maka alternatif jawaban diberi skor yakni sangat baik $=5$, baik $=4$, cukup $=3$, kurang $=2$, sangat kurang $=1$. Kisikisi pengembangan instrumen tampak pada Tabel 1 berikut.

Tabel 1. Kisi-kisi Instrumen Validasi LKPD

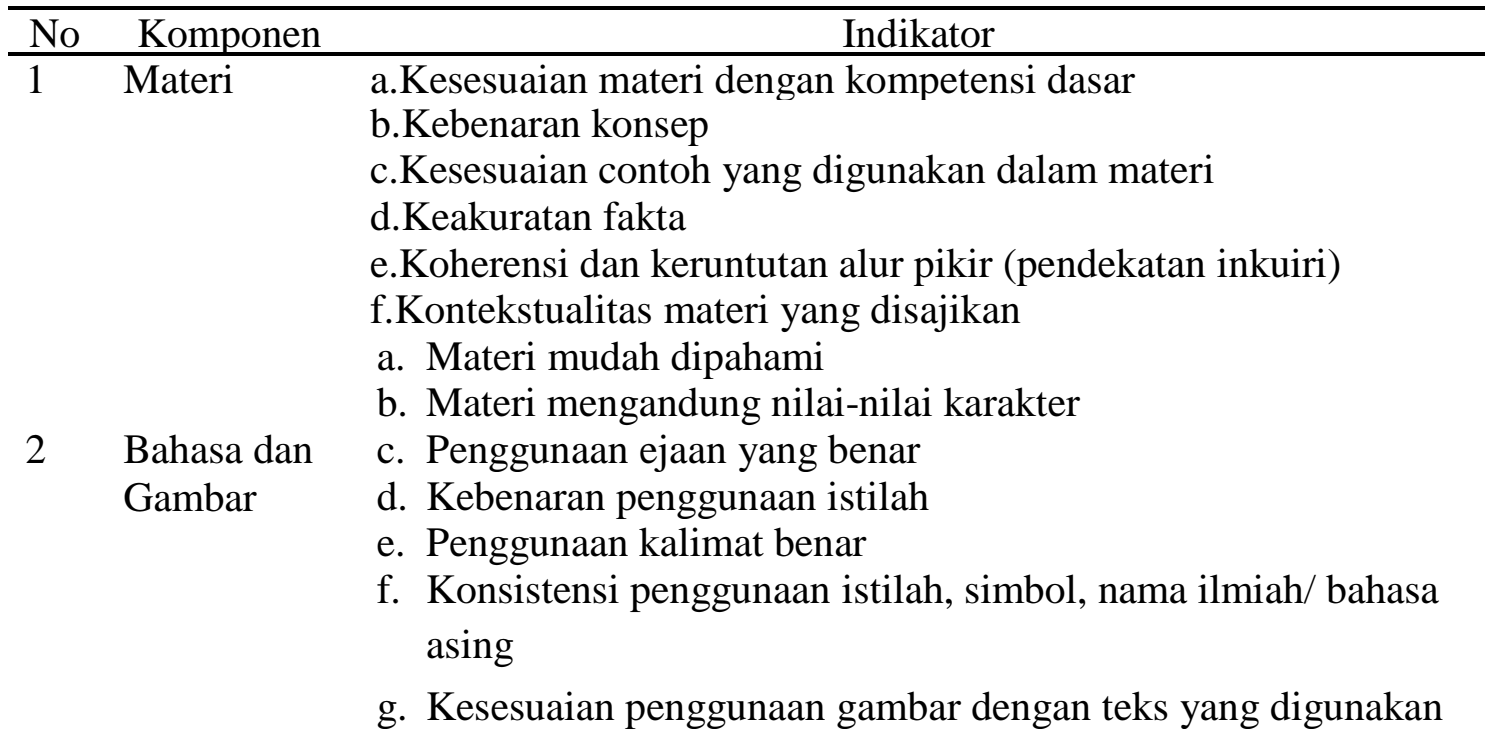


DOI: https://doi.org/10.24127/ajpm.v8i1.1740

3 Penyajian

h. Kesesuaian penggunaan bahasa atau gambar dengan perkembangan kognisi

i. Kejelasan media gambar

j. Kelengkapan keterangan gambar

a. Penyajian materi secara logis

b. Penyajian materi secara sistematis

c. Penyajian materi familiar dengan siswa

d. Penyajian materi menimbulkan suasana menyenangkan

e. Penyajian materi dilengkapi dengan gambar

f. Penyajian mendorong siswa kreatif

g. Penyajian dapat menuntun siswa berpikir kritis

h. Penyajian dapat menuntun siswa untuk menggali informasi

i. Penyajian dapat menuntun kecakapan pembaca dalam memecahkan masalah

j. Penyajian dapat menuntun siswa untuk mengambil keputusan

k. Penyajian gambar

1. Penyajian rangkuman materi

m. Penyajian glosarium

n. Penyajian daftar pustaka

4 Tampilan

a. Kesesuaian proporsi gambar dengan bahasa paparan

b. Keterbacaan teks atau tulisan

c. Kesesuaian ukuran gambar

d. Kesesuaian warna gambar

e. Kesesuaian bentuk gambar

Analisis data hasil penelitian dilakukan dengan menggunakan pendekatan kualitatif dan kuantitatif. Data berupa saran dan kritik dari ahli/pakar dan peserta didik dianalisis dengan pendekatan kualitatif, sedangkan data kelayakan LKPD dan pendapat mengenai kesesuaian LKPD diolah dengan pendekatan deskriptif kuantitatif. Untuk menganalisis data tentang kelayakan LKPD dilakukan dengan langkah-langkah sebagai berikut:
a. Melakukan tabulasi data hasil penilaian
b. Menghitung rata-rata skor tiap indikator dengan rumus:

$$
X=\frac{\sum X}{N}
$$

keterangan :

$$
\begin{array}{ll}
x & =\text { skor rata-rata } \\
\sum_{\text {coba }} \mathrm{X} & =\text { jumlah subjek uji } \\
N & =\text { jumlah skor }
\end{array}
$$

c. Menjumlahkan rata-rata skor tiap aspek $(P)$

d. Menginterpretasi secara kualitatif jumlah rata-rata skor tiap aspek dengan menggunakan rumus konversi skor skala 5 pada Tabel 2 . 
DOI: https://doi.org/10.24127/ajpm.v8i1.1740

Tabel 2. Pedoman Konversi Jumlah Rata-rata skor menjadi nilai dengan lima kategori

\begin{tabular}{rlrl}
\hline No & \multicolumn{1}{c}{ Rentang Skor } & Nilai & \multicolumn{1}{c}{ Kategori } \\
\hline 1 & $M i+1,5 S b i<P$ & A & Sangat Baik \\
2 & $M i+0,5 S b i<P \leq M i+1,5 S b i$ & B & Baik \\
3 & $M i-0,5 S b i<P \leq M i+0,5 S b i$ & C & Cukup Baik \\
4 & $M i-1,5 S b i<P \leq M i-0,5 S b i$ & D & Kurang \\
5 & $P \leq M i-1,5 S b i$ & E & Sangat Kurang \\
\hline
\end{tabular}

Sumber: Azwar (2009: 163)

Keterangan:

$P=$ mean ideal

Skor maksimal ideal $=$ jumlah indikator

x skor tertinggi

Skor Minimal ideal $=$ jumlah indikator $\mathrm{x}$ skor terendah

$M i=$ mean ideal $=1 / 2$ (skor mak ideal + skor Min ideal)

$S b i=$ simpangan baku ideal $=1 / 6$ (skor mak-skor Min)

\section{HASIL PENELITIAN DAN PEMBAHASAN}

Penyelesaian penelitian ini dilakukan berdasarkan tahapan prosedur penelitian pengembangan yang diadaptasi dari prosedur pengembangaan Borg and Gall, yaitu pengumpulan informasi, perencanaan, penyusunan, pengembangan draft produk dan penilaian. Dalam pelaksanaanya, peneliti memiliki beberapa hambatan. Pertama, pada tahap pembuatan panduan penggunaan Cabri $3 D$, penyelasaian pembuatan panduan penggunaan Cabri $3 D$ memerlukan waktu yang cukup lama karena dalam pembuatannya memerlukan keahlian yang khusus dan sumber terkait tata cara penggunaan Cabri $3 D$ juga sangat terbatas. Kedua, pada saat teknis uji coba terdapat beberapa komputer yang rusak sehinggan peserta didik harus menggunakan satu komputer untuk 2 orang.

Selain hambatan, ada pula kemudahan dalam penelitian pengembangan ini, yaitu pada tahap analisis data hasil uji coba lapangan. Analisis data hasil dari penelitian pengembangan menggunakan perhitungan sederhana sehingga memudahkan dalam perhitungan. LKPD berbasis Cabri $3 D$ yang merupakan salah satu perangkat pembelajaran matematika ini telah diuji cobakan terhadap 22 peserta didik SMP IT Gameel Akhlaq kelas VIII. Dalam pelaksanaan uji coba, peserta didik sangat antusias karena proses pembelajaran tidak hanya terpaku pada lembar kerja, meliankan penggunaan media berbentuk software matematika yang memiliki keunggulan dalam mempermudah memahami konsep-konsep matematika yang bersifat abstrak terutama materi geometri. Peserta didik juga sangat terlihat antusias dan termotivasi dalam proses pembelajaran, itu terlihat dari tingkat keaktifan peserta didik dalam bertanya dan merespon setiap masalah yang ada pada lembar kerja.

Berdasarkan analisis validasi yang dilakukan oleh ahli materi, diperoleh hasil seperti yang tercantum pada Tabel 3. Sedangkan hasil analisis validasi yang dilakukan oleh ahli media ditunjukkan oleh Tabel 4. 
DOI: https://doi.org/10.24127/ajpm.v8i1.1740

Tabel 3. Analisis Hasil Validasi Ahli Materi

\begin{tabular}{llcccc}
\hline No & \multicolumn{1}{c}{ Aspek } & $\begin{array}{c}\text { Jumlah } \\
\text { Skor } \\
\text { Penilaian }\end{array}$ & $\begin{array}{c}\text { Rata-rata } \\
\text { Skor }\end{array}$ & $\begin{array}{c}\text { Nilai } \\
\text { Kualitatif }\end{array}$ & Kategori \\
\hline 1 & Kualitas Materi & 59 & 4,54 & A & Sangat Baik \\
2 & Kualitas Pembelajaran & 45 & 4,50 & A & Sangat Baik \\
\hline
\end{tabular}

Tabel 4. Analisis Hasil Validasi Ahli Media

\begin{tabular}{llcccc}
\hline No & Aspek & $\begin{array}{c}\text { Jumlah Skor } \\
\text { Penilaian }\end{array}$ & $\begin{array}{c}\text { Rata-rata } \\
\text { Skor }\end{array}$ & $\begin{array}{c}\text { Nilai } \\
\text { Kualitatif }\end{array}$ & Kategori \\
\hline 1 & Aspek Media & 35 & 4,38 & A & Sangat Baik \\
2 & Aspek Tampilan & 81 & 4,26 & A & Sangat Baik \\
\hline
\end{tabular}

Berdasarkan Tabel 3 dan Tabel 4, diketahui bahwa media pembelajaran termasuk dalam kategori sangat baik pada aspek kualitas materi, kualitas pembelajaran, media dan aspek tampilan. Masukan- masukan yang diperoleh dari ahli media dijadikan acuan revisi produk tahap I.

Berdasarkan data hasil penilaian yang dilakukan oleh guru sebagai praktisi, diketahui bahwa jumlah skor penilaian oleh guru mata pelajaran matematika adalah sebesar 59 dengan rata- rata skor 4,21 pada aspek kualitas materi, dan pada aspek kualitas pembelajaran memperoleh skor 43 dengan rata-rata skor 4,3. Selanjutnya skor dikonversi ke dalam nilai kualitatif (A-E), sehingga diketahui kualitas media berdasarkan penilaian guru mata pelajaran matematika. Hasil analisis data validasi ahli materi diuraikan dalam Tabel 5.

Tabel 5. Analisis Hasil Penilaian Guru Matematika

\begin{tabular}{clcccc}
\hline No & \multirow{2}{*}{ Aspek } & $\begin{array}{c}\text { Jumlah } \\
\text { Skor Penilaian }\end{array}$ & $\begin{array}{c}\text { Rata-rata } \\
\text { Skor }\end{array}$ & $\begin{array}{c}\text { Nilai } \\
\text { Kualitatif }\end{array}$ & Kategori \\
\hline 1 & Kualitas Materi & 59 & 4,2 & A & Sangat Baik \\
2 & Kualitas Pembelajaran & 43 & 4,3 & A & Sangat Baik \\
\hline
\end{tabular}

Berdasarkan Tabel 5, diketahui bahwa media pembelajaran termasuk dalam kategori sangat baik pada aspek kualitas materi dan aspek kualitas pembelajaran. Masukanmasukan yang diperoleh penilaian guru bidang studi dijadikan acuan revisi produk tahap II.
Uji coba lapangan diberikan pada 22 peserta didik SMP kelas VIII. Adapun analisis penilaian peserta didik terhadap penggunaan lembar kerja peserta Didik berbasi Cabri 3D terangkum dalam diagram yang ditunjukkan oleh Gambar 3. 


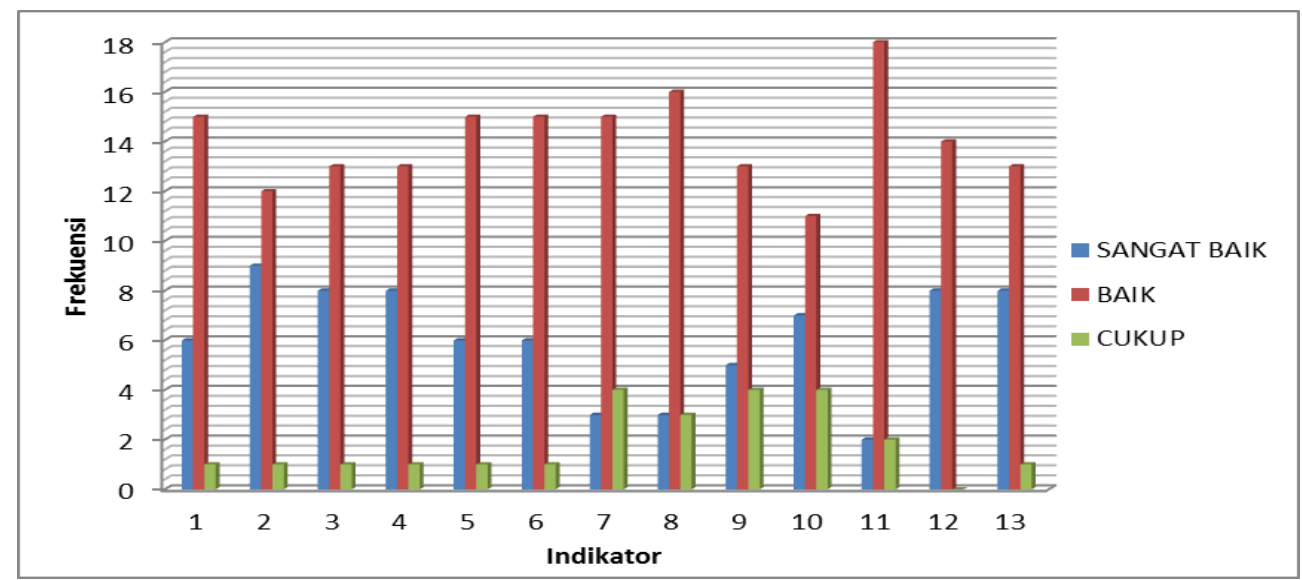

Gambar 3. Sebaran data frekuensi penilaian peserta didik

\section{KESIMPULAN DAN SARAN}

Berdasarkan hasil penelitian yang telah dilakukan, maka dapat diperoleh kesimpulan yaitu LKPD yang telah dikembangkan dapat meningkatkan pemahaman konsep matematis siswa khususnya pada materi geometri. LKPD berbasis Cabri $3 D$ juga mempermudah siswa dalam penggunaan Cabri $3 D$ sehingga proses pembelajaran menjadi lebih efektif dan efisien.

\section{DAFTAR PUSTAKA}

Akhirni, A., \& Mahmudi, A. (2015). Pengaruh pemanfaatan cabri 3D dan geogebra pada pembelajaran geometri ditinjau dari hasil belajar dan motivasi. Jurnal Pendidikan Matematika dan Sains, 3(2), 91-100.

Azwar, S. (2009). Sikap Manusia, Teori dan Pengukurannya. Yogyakarta: Pustaka Pelajar.

Baki, A., Kosa, T., \& Guven, B. (2011). A comparative study of the effects of using dynamic geometry software and physical manipulatives on the spatial visualisation skills of pre-service mathematics teachers. British Journal of Educational Technology.

https://doi.org/10.1111/j.14678535.2009.01012.x
E, Widiyaningsih. E, P. (2013). Keefektifan Pembelajaran Model Quantum Teaching Berbantuan Cabri 3D Terhadap Kemampuan Pemecahan Masalah. Jurnal Kreano.

Gürbüz, R., \& Gülburnu, M. (2013). Effect of Teaching Geometry with Use Cabri 3D in Eighth Grade on Conceptual Learning. Turkish Journal of Computer and Mathematics Education (TURCOMAT). https://doi.org/10.16949/turcomat.6 0325

Hartatiana, H., Darhim, D., \& Nurlaelah, E. (2017). Improving Junior High School Students' Spatial Reasoning Ability Through Model Eliciting Activities with Cabri 3D. International Education Studies. https://doi.org/10.5539/ies.v11n1p1 48

Istitho'ah, I. (2017). Pengembangan Media Pembelajaran Berbasis Kontekstual Berbantuan Software Cabri 3D dan Prezi Dengan Teori Konstruktivisme Pada Kubus Dan Balok. AKSIOMA. https://doi.org/10.26877/aks.v7i2.14 15

Kösa, T., \& Karakuş, F. (2010). Using dynamic geometry software Cabri 
AKSIOMA: Jurnal Program Studi Pendidikan Matematika

DOI: https://doi.org/10.24127/ajpm.v8i1.1740

3D for teaching analytic geometry. In Procedia - Social and Behavioral Sciences.

https://doi.org/10.1016/j.sbspro.201 0.03 .204

Oldknow, A., \& Tetlow, L. (2008). Using dynamic geometry software to encourage $3 \mathrm{D}$ visualisation and modelling. The Electronic Journal of Mathematics \& Technology [Electronic Only].

Priatna, N. (2017). Students' Spatial Ability through Open-Ended Approach Aided by Cabri 3D. In Journal of Physics: Conference Series.

https://doi.org/10.1088/17426596/895/1/012065

Sari, D. P. (2018). Pengaruh Model Pembelajaran Tipe Numbered Heads Together terhadap Kemampuan Pemahaman Konsep Matematika. Jurnal Mathematic Paedagogic, 2(2), 196-203.

Yeni, E.M. (2011). Pemanfaatan bendabenda manipulatif untuk meningkatkan pemahaman konsep geometri dan kemampuan tilikan ruang siswa kelas $\mathrm{V}$ sekolah dasar. Jurnal Edisi Khusus, 1, pp.63-75. 